\title{
Which Foetal-Pelvic Variables Are Useful for Predicting Caesarean Section and Instrumental Assistance?
}

\author{
P. Frémondière ${ }^{a, b} \quad$ L. Thollon ${ }^{c} \quad$ P. Adalian ${ }^{b} \quad$ J. Delotte $^{d} \quad$ F. Marchal ${ }^{b}$ \\ a Department of Obstetrics and Gynecology, St Joseph Hospital, ${ }^{b}$ Physical Anthropology Laboratory (UMR 7268, \\ Droit, Éthique et Santé ADÉS-AMU/CNRS/EFS), ' Applied Biomechanics Laboratory (UMR-T24), Marseille, and \\ ${ }^{d}$ Department of Obstetrics and Gynecology, I'Archet Hospital, Nice, France
}

\section{Significance of the Study}

- The use of the obstetric conjugate diameter in the prediction of caesarean section was not useful.

- Sub-pubic angle, antero-posterior outlet, and bi-parietal diameters were relevant for the prediction of instrumental assistance. In clinical practice, these variables should be considered for predicting the mode of delivery.

\section{Keywords}

Foetal-pelvic disproportion · Pelvimetry · Caesarean

delivery · Assisted delivery · Pelvic scan

\begin{abstract}
Objective: To assess the variables useful to predict caesarean delivery (CD) and instrumental assistance, through the analysis of a large number of foetal-pelvic variables, using discriminant analysis. Materials and Methods: One hundred and fourteen pregnant women were included in this singlecentre prospective study. For each mother-foetus pair, 43 pelvic and 18 foetal variables were measured. Partial least squares-discriminant analysis was performed to identify foetal-pelvic variables that could statistically separate the 3 delivery modality groups: spontaneous vaginal delivery (SVD), $C D$, and instrument-assisted delivery (IAD). Results: For the $S V D$ versus $C D$ model, voluminous foetuses and women with
\end{abstract}

\begin{tabular}{|c|c|}
\hline KARGER & $\begin{array}{l}\text { Karger } \\
\text { Open access }\end{array}$ \\
\hline $\begin{array}{l}\text { E-Mail karger@karger.com } \\
\text { www.karger.com/mpp }\end{array}$ & $\begin{array}{l}\text { This is an Open Access article licensed under the terms of the } \\
\text { Creative Commons Attribution-NonCommercial 3.0 Un- } \\
\text { ported license (CC BY-NC) (www.karger.com/OA-license), } \\
\text { applicable to the online version of the article only. Distribu- } \\
\text { tion permitted for non-commercial purposes only. }\end{array}$ \\
\hline
\end{tabular}

a narrow pelvic inlet had a greater risk for requiring $C D$. The most efficient variables for discrimination were the transverse diameter and foetal weight. The antero-posterior inlet and obstetric conjugate were considered in this model, with the former being a useful variable but not the latter. For the SVD versus IAD model, the most important variables were the foetal variables, particularly the bi-parietal diameter. Women with a reduced antero-posterior outlet diameter and a narrow pubic arch were more at risk of requiring an IAD. Conclusion: The antero-posterior inlet was an efficient variable unlike the obstetric conjugate. The obstetric conjugate diameter should no longer be considered a useful variable in estimating the arrest of labour. Antero-posterior inlet diameter was a sagittal variable that should be taken into account. The comparison of sub-pubic angle and bi-parietal and antero-posterior outlet diameters was useful in identifying a risk of requiring instrumental assistance.

(c) 2017 S. Karger AG, Basel

Pierre Frémondière

UMR 7268 Faculté de Médecine, Secteur Nord Batiment A

CS80011 Bd Pierre Dramard

FR-13344 Marseille Cedex 15 (France)

E-Mail pierrefremondiere@yahoo.fr 


\section{Introduction}

Foetal-pelvic disproportion and the arrest of labour are the indications of $40-50 \%$ of caesarean deliveries (CDs) $[1,2]$. To predict the foetal-pelvic disproportion, pelvimetry and ultrasound are conventionally used. But assessments of the foetal-pelvic disproportion with these 2 examinations provide low predictive values in clinical practice $[3,4]$.

The consequence of these low predictive values is the declining use of pelvimetry. In addition, women who underwent radiographic pelvimetry had an increased risk of $\mathrm{CD}$ [5]. Currently, the most reliable procedure for estimating a good match between the foetus size and the maternal pelvis is the trial of labour [6]. However, the prediction of foetal-pelvic disproportion is still important because a CD performed during labour generally leads to a higher morbidity than a CD performed before the beginning of labour [7].

Attempts have been made to identify a method that could accurately predict foetal-pelvic disproportion, but no study has yet reported on the usefulness of a large dataset of foetal-pelvic variables for this prediction. The objective of this study was to analyse the variability of the foetal-pelvic relationship from an anatomical perspective and its consequences on clinical outcomes, and to suggest which pelvic and foetal variables could predict foetal-pelvic disproportion.

\section{Materials and Methods}

\section{Sample and Foetal-Pelvic Variables}

One hundred and fourteen women at Saint Joseph Hospital, Marseille, France, were recruited from 29 March 2011 to 10 December 2013 for this single-centre study. The women were recruited from 10,597 deliveries in the hospital, shown in the flow chart (Fig. 1). The inclusion criterion was birth at term with the foetus in a cephalic presentation. Exclusion criteria were CD performed in cases of abnormal foetal heart rate or before $2 \mathrm{~h}$ of arrest of labour, abnormal uterine contraction, twin pregnancies, and iterative CD. The other deliveries excluded from the study were 10,198 with no CT scan, 133 for whom the CT scan was not available, 52 with breech presentation, and 78 who underwent caesarean section before the onset of labour. The indications for these 78 caesarean sections before the onset of labor were macrosomia in 19 cases, rupture of membranes without labour in 8, post-term pregnancies without labour in $7, \mathrm{CD}$ by maternal request in $4, \mathrm{CD}$ for the prevention of uterine rupture in 3 , and an iterative CD in 37. The 114 deliveries included in the study were spontaneous vaginal delivery (SVD) in 51 cases, instrument-assisted delivery (IAD) in 38 , and CD for the arrest of labour in 25. All 114 women had both epidural anaesthesia and a pelvic scan, i.e., radiological measurement of the parameters of the pelvis, before delivery. The centre has 3 protocols for pelvic scanning, based on patient adiposity: low $(100 \mathrm{kV}, 25 \mathrm{~mA})$, standard $(100 \mathrm{kV}, 35 \mathrm{~mA})$, and high $(120 \mathrm{kV}, 35$ $\mathrm{mA}$ ) adiposity. These 3 protocols produce low-level irradiation in the range of $15-35 \mathrm{mGy} / \mathrm{cm}$. Indications for a pelvic scan were a scarred uterus, a breech presentation (cephalic presentation at the beginning of labour), and suspicion or a history of foetal-pelvic disproportion. All patients enrolled in the study had the benefits/ risks and long-term risks of CT scanning explained and all gave their consent for the scanning. Scans were performed with a 16-slice Siemens SOMATOM Definition Flash strip scanner located in the Medical Imaging Department of our hospital. The intersection gap was $0.6-1 \mathrm{~mm}$. One operator (P.F.) performed all the pelvic diameter measurements with Amira 5.0.0 software (FEI

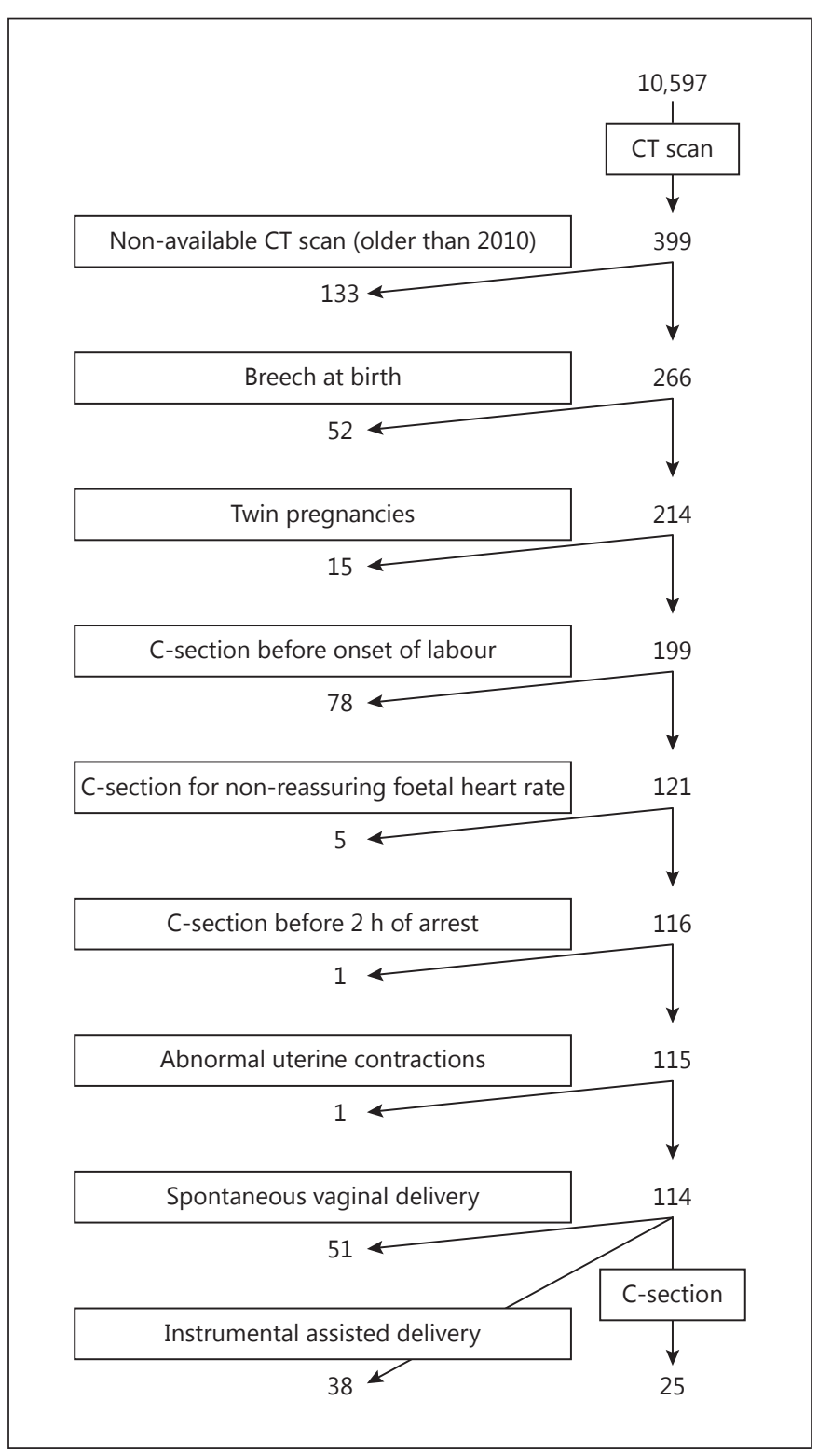

Fig. 1. Flow chart of the study. C-section, caesarean section. 
Visualization Sciences Group, Zuse Institute Berlin). A total of 43 pelvic variables were considered. An example of the pelvis reconstruction and inlet measurements performed is shown in Figure 2. For 40/114 pelvic scans, 2 sets of measurements were performed for each pelvic variable, 1 year apart.

The operator (P.F.) was blinded to the first set of measurements while conducting the second set. Intra-observer assessment was then compared to assess the standard error of measurement (SEM) $[8,9]$, i.e., the square root of the variance (or standard deviation). Measurements with an SEM of $\leq 4 \mathrm{~mm}$ are deemed accurate and those outside this range considered inaccurate [8]. Korhonen et al. [9] considered a cut-off of $\geq 5 \mathrm{~mm}$. Based on these previous studies, variables with a standard deviation of $>4 \mathrm{~mm}$ were excluded. To estimate the reliability of angle measurement, the intra-class correlation coefficient (ICC) was chosen as recommended by Imai et al. [10], to consider only angles that are moderately-to-substantially reliable, i.e., with an ICC $>0.31$.

The newborn measurements were performed during the postpartum period using anthropometric tools (a cephalometric compass, a tape measure, and a newborn scale). Eighteen foetal variables were measured (Fig. 3). This study was approved by the South Mediterranean II Ethical Committee for the Protection of Persons and written informed consent was obtained from all the patients.

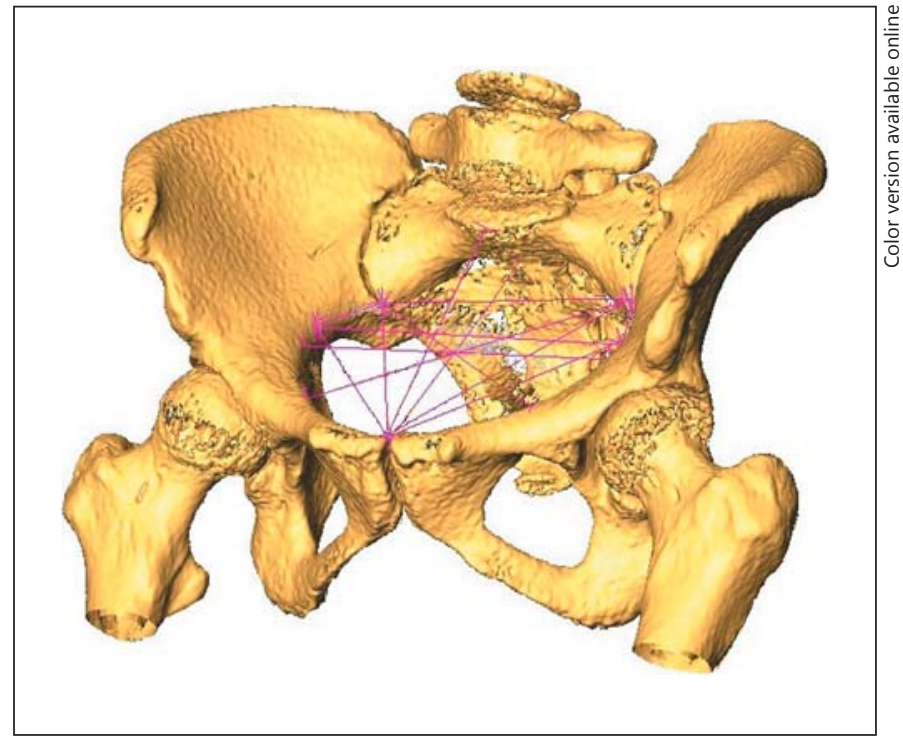

Fig. 2. An example of pelvis reconstruction and inlet measurements.

Table 1. Maternal and foetal data and characteristics of labour

\begin{tabular}{|c|c|c|c|c|c|}
\hline & $\operatorname{SVD}(n=51)$ & $\operatorname{IAD}(n=38)$ & $\mathrm{CD}^{\mathrm{a}}(n=25)$ & Total $(n=114)$ & $p$ value \\
\hline \multicolumn{6}{|l|}{ Maternal characteristics } \\
\hline Height, $\mathrm{cm}$ & $163.0 \pm 7.0$ & $162.6 \pm 5.9$ & $160.4 \pm 6.0$ & $162.1 \pm 6.5$ & 0.22 \\
\hline Age, years & $32.3 \pm 5.1$ & $31.3 \pm 4.2$ & $32.7 \pm 5.1$ & $31.9 \pm 4.4$ & 0.37 \\
\hline BMI & $25.2 \pm 6.7$ & $23.3 \pm 4.5$ & $24.8 \pm 4.9$ & $24.4 \pm 5,4$ & 0.26 \\
\hline Parity & $2[0]$ & $2[0.5]$ & $2[0]$ & $2[0]$ & 0.06 \\
\hline Gravidity & $2[0]$ & $2[0]$ & $2[0]$ & $2[0]$ & 0.06 \\
\hline Nulliparous & $5(10)$ & $9(24)$ & $5(20)$ & $19(17)$ & 0.20 \\
\hline Previous uterine scar & $36(70)$ & $28(73)$ & $18(72)$ & $82(72)$ & 0.06 \\
\hline GA at birth, weeks & $39.2 \pm 1.1$ & $39.8 \pm 1.1$ & $39.7 \pm 1$ & $39.5 \pm 1.1$ & 0.12 \\
\hline \multicolumn{6}{|l|}{ Characteristics of labour } \\
\hline Induced & $10(19)$ & $10(26)$ & $9(36)$ & $29(25)$ & 0.09 \\
\hline Oxytocin, IU & $0.3[0.8]$ & $1.1[2.0]$ & $0.4[1.2]$ & $0.5(1.4)$ & 0.04 \\
\hline \multicolumn{6}{|l|}{ Foetal head engagement } \\
\hline Occiput anterior ${ }^{\mathrm{b}}$ & $37(72)$ & $33(87)$ & $0(0)$ & $70(61)$ & 0.10 \\
\hline Transverse & $1(2)$ & $1(3)$ & $0(0)$ & $2(2)$ & 0.83 \\
\hline Occiput posterior $^{\mathrm{c}}$ & $7(14)$ & $4(10)$ & $0(0)$ & $11(10)$ & 0.65 \\
\hline Unknown & $6(12)$ & $0(0)$ & $25(100)$ & $31(27)$ & 0.029 \\
\hline \multicolumn{6}{|l|}{ Duration } \\
\hline 1st stage, h & $3.0[2.1]$ & 3.5 [1.9] & $3.6[2.7]$ & $3.0[3.1]$ & $<0.001$ \\
\hline 2nd stage, $\mathrm{h}$ & $1.0[1.3]$ & $1.5[1.6]$ & $0[0]$ & $1.5[2.2]$ & $<0.001$ \\
\hline \multicolumn{6}{|l|}{ Neonatal characteristics } \\
\hline Birth weight, g & $3,287 \pm 403$ & $3,400 \pm 478$ & $3,735 \pm 547$ & $3,433 \pm 489$ & 0.001 \\
\hline APGAR score at $5 \mathrm{~min}$ & $10[0]$ & $10[0]$ & $10[0]$ & $10[0]$ & 0.74 \\
\hline \multicolumn{6}{|c|}{$\begin{array}{l}\text { Values are expressed as mean } \pm \mathrm{SD}, n(\%) \text {, or median }[\mathrm{IQR}] \text {. SVD, spontaneou } \\
\mathrm{CD} \text {, caesarean delivery; BMI, body mass index; GA, gestational age. } \\
{ }^{\mathrm{a}} \text { Caesarean sections were performed before the onset of } 2 \text { nd stage of labour. } \\
{ }^{\mathrm{b}} \text { Left occiput anterior + occiput anterior + right occiput anterior. } \\
{ }^{\mathrm{c}} \text { Left occiput posterior + occiput posterior + right occiput posterior. }\end{array}$} \\
\hline
\end{tabular}



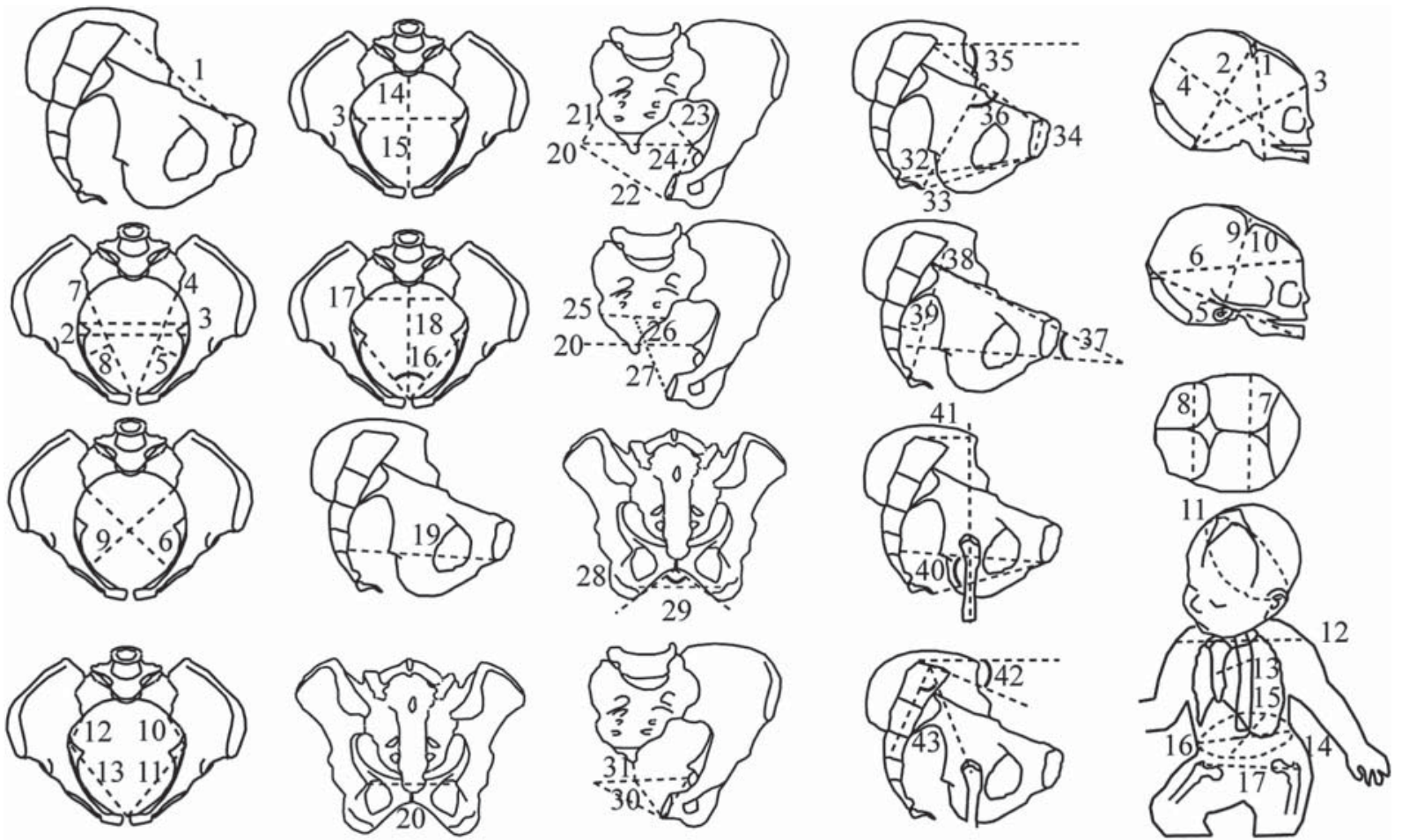

1: Obstetric conjugate (oc)

2: Medial transverse inlet (meti)

3: Maximal transverse inlet (mati)

24: Left midplane anterior space (Imas)

25: Midplane sacral breadth ( $\mathrm{msb}$ )

26: Sagittal posterior midplane (spm)

4: Left ilio-pectineal cord length(licl)

5: Left ilio-pectineal cord subtense (lics)

6: Right oblique inlet (roi)

7: Right ilio-pectineal cord length (ricl)

8: Right ilio-pectineal cord subtense (rics)

9: Left oblique inlet (loi)

10: Left inlet posterior space (lips)

11: Left inlet anterior space (lias)

12: Right inlet posterior space (rips)

13: Right inlet anterior space (rias)

14: Sagittal posterior inlet (spi)

15: Sagittal anterior inlet (sai)

16: Pectineal angle (pa)

17: Inlet sacral breadth (isb)

18: Inlet antero-posterior (iap)

19: Midplane antero-posterior (map)

20: Interspinous (isp)

21: Right midplane posterior space ( $\mathrm{rmps}$ )

22: Right midplane anterior space (rmas)

23: Left midplane posterior space (Imps)

27: Sagittal anterior midplane (sam)

28: Transverse outlet (tout)

29: Subpubic angle (spa)

30: Sagittal anterior outlet (sao)

31: Sagittal posterior outlet (spo)

32: Outlet antero-posterior (oap)

33: Pubococcygeus length ( $\mathrm{pcl}$ )

34: Pubic symphysis height (psh)

35: Obstetric conjugate slope (ocs)

36: Obstetric conjugate-umbiliccoccygeal angle (ocua)

37: Inlet-midplane angle (ima)

38: Sacral cord length (scl)

39: Sacral cord subtense (scs)

40: Midplane-outlet angle (moa)

41: Sacral overhang (over)

42: Sacral slope (sslop)

43: Sacral incidence (inc)
Foetus

1: submentobregmatic (smb)

2: suboccipitobregmatic (sob)

3: suboccipitofrontal (sof)

4: mentovertical (mv)

5: mento-occipital (moc)

6: occipitofrontal (of)

7: biparietal (bip)

8: bitemporal (bit)

9: right tragion-bregma ( $\mathrm{rtb}$ )

10: left tragion-bregma (Itb)

11: suboccipitobregmatic circumference (soc)

12: biacromial (bia)

13: sternum-thoracic vertebral (stv)

14: abdominal circumference (abdc)

15: abdominal sagittal (abds)

16: transverse abdominal (abdt)

17: bitrochanterian (bih)

18: birthweight (wght, not on figure)

Fig. 3. Foetal-pelvic variables. 
Table 2. Intra-observer measurement error of the 43 pelvic variables

\begin{tabular}{ll} 
& \\
\hline Variable (abbreviation) & \\
\hline Obstetric conjugate (oc) & $1.5 \pm 1.3$ \\
Medial transverse inlet (meti) & $1.8 \pm 1.5$ \\
Maximum transverse inlet (mati) & $1.2 \pm 1.0$ \\
Left ilio-pectineal cord length (licl) & $2.3 \pm 1.9$ \\
Left ilio-pectineal cord subtense (lics) & $1.5 \pm 1.7$ \\
Left oblique inlet (loi) & $2.1 \pm 1.4$ \\
Right ilio-pectineal cord length (ricl) & $2.1 \pm 1.9$ \\
Right ilio-pectineal cord subtense (rics) & $1.3 \pm 1.3$ \\
Right oblique inlet (roi) & $1.7 \pm 1.4$ \\
Left inlet posterior space (lips) & $2.7 \pm 2.8$ \\
Left inlet anterior space (lias) & $2.9 \pm 2.3$ \\
Right inlet posterior space (rips) & $2.8 \pm 2.7$ \\
Right inlet anterior space (rias) & $2.1 \pm 2.2$ \\
Sagittal anterior inlet (sai) & $3.0 \pm 3.1$ \\
Sagittal posterior inlet (spi) & $3.6 \pm 3.6$ \\
Pectineal angle (pa) & $2.1(0.84)$ \\
Inlet sacral breadth (isb) & $2.0 \pm 1.5$ \\
Inlet antero-posterior (iap) & $2.1 \pm 2.6$ \\
Mid-plane antero-posterior (map) & $2.6 \pm 2.6$ \\
Inter-spinous (isp) & $2.3 \pm 2.7$ \\
Right mid-plane posterior space (rmps) & $3.4 \pm 2.6$ \\
Right mid-plane anterior space (rmas) & $1.5 \pm 1.3$ \\
Left mid-plane posterior space (lmps) & $3.3 \pm 2.6$ \\
Left mid-plane anterior space (lmas) & $2.2 \pm 1.9$ \\
Mid-plane sacral breadth (msb) & $8.4 \pm 7.3$ \\
Sagittal posterior mid-plane (spm) & $2.4 \pm 2.7$ \\
Sagittal anterior mid-plane (sam) & $2.0 \pm 2.0$ \\
Pubic sympysis height (psh) & $2.9 \pm 2.3$ \\
Outlet antero-posterior (oap) & $3.8 \pm 3.1$ \\
Pubococcygeus length (pcl) & $2.3 \pm 1.9$ \\
Obstetric conjugate slope (ocs) & $2.0(0.88)$ \\
Obstetric conjugate-umbilico-coccygeal angle (ocua) & $7.8(0.45)$ \\
Inlet-midplane angle (ima) & $3.8(0.34)$ \\
Sacral cord length (scl) & $3.4 \pm 3.9$ \\
Sacral cord subtense (scs) & $2.6 \pm 2.7$ \\
Sacral overhang (over) & $1.5 \pm 1.3$ \\
Sacral slope (sslop) & $3.5(0.81)$ \\
Sacral incidence (inc) & $5.4(0.7)$ \\
Mid-plane-outlet angle (moa) & $4.5(0.35)$ \\
Transverse outlet (tout) & $1.9 \pm 1.7$ \\
Sub-pubic angle (spa) & $2.0(0.93)$ \\
Sagittal anterior outlet (sao) & \\
Sagittal posterior outlet (spo) & \\
& \\
&
\end{tabular}

Intra-observer measurement error is expressed as mean $\pm \mathrm{SD}$ in millimetres. Other values are expressed as mean (ICC) in degrees.

${ }^{1}$ The variable with an intra-observer error of $>4 \mathrm{~mm}$.
Statistical Analyses

To identify relevant variables in the prediction of the foetalpelvic disproportion, partial least squares-discriminant analysis (PLS-DA) was used. This is commonly performed to statistically separate 2 groups, e.g, eutocia versus dystocia, by simultaneously using a large number of predictors common to both groups, i.e., in this case, the foetal-pelvic variables [11].

In this study, 2 PLS-DA were performed, taking into account the different types of delivery: CD versus SVD and IAD versus SVD. The value of the variable importance in the projection (VIP) quantified for the usefulness of each independent variable, allowing for discrimination between groups; only foetal-pelvic variables with a VIP value of $>1$ were considered useful for discrimination [11]. The significance of differences between the groups was tested using the Kruskal-Wallis test. The $p$ value $<0.05$ was considered statistically significant. Statistical tests were performed using XLSTAT 2013.1.02 software (Addinsoft, 2013).

\section{Results}

The obstetric characteristics of the study sample are presented in Table 1. The median duration of the first stage of labour was shorter for the SVD group $(3 \mathrm{~h})$ than the IAD group $(3.5 \mathrm{~h})$, indicating that the CD group had the longest duration of the first phase of labour ( $3.6 \mathrm{~h})$. The median duration of the second stage of labour was shorter for the SVD group $(1 \mathrm{~h})$ than the IAD group $(1.5 \mathrm{~h})$. The SVD group had the lowest birth weights $(3,287 \pm 403 \mathrm{~g})$, followed by the $\operatorname{IAD}(3,400 \pm 478 \mathrm{~g})$ group, and then the CD group $(3,735 \pm 547 \mathrm{~g})$. The duration of the first and second stages of labour and the birth weight were statistically different in the 3 groups.

Intra-observer measurement errors are presented in Table 2. The variable "inlet sacral breadth" had an intraerror value $>4 \mathrm{~mm}$. For angle measurements, the ICC lay between 0.34 (inlet mid-plane angle) and 0.93 (sub-pubic angle). Consequently, all angle measurements were considered in our analysis.

The PLS-DA results are presented in Table 3. In these analyses, the percentage of good ranking in both the eutocia and dystocia groups was calculated. Of the 76 SVD and CD cases, 64 (84\%) were well predicted and of the 89 SVD and IAD cases, $63(71 \%)$ were well predicted.

The PLS-DA provides an assessment of the most important discriminant variables. The classification of the foetal-pelvic variables in the SVD versus CD model is shown in Figure 4. Of the 30 important variables, 14 (47\%) were foetal variables, with weight being the most important variable. Of the remaining 16 variables, 12 (75\%) corresponded to pelvic features defined by the inlet

Med Princ Pract 2017;26:359-367 DOI: $10.1159 / 000477732$

Foetal-Pelvic Variables 
variables, and 4 (25\%) corresponded to pelvic features defined by the mid-plane and outlet variables. The most important variable was the medial transverse inlet diameter. Among the mid-plane and outlet variables, the inter-spinous diameter had the highest VIP value.

The classification of the foetal-pelvic variables in the SVD versus IAD model is shown in Figure 5 . Of the 20 important variables, 13 (65\%) were foetal variables, with the bi-parietal diameter being the most important variable. Of the remaining 7 variables, 6 (86\%) corresponded to pelvic features defined by the mid-plane or outlet variables, and 1 (14\%) corresponded to pelvic features defined by the inlet. The most important variable was the antero-posterior outlet diameter. Women with a small antero-posterior outlet diameter, a large obstetric conjugate, and a narrow pubic arch were at a greater risk of requiring IAD.

\section{Discussion}

In this study, we found that a large foetus and a narrow pelvic inlet were associated with labour dystocia requiring $\mathrm{CD}$. These findings confirmed those of previous studies $[7,12-17]$, in which it was reported that CD for the arrest of labour corresponded with the inability for a large foetus to deal with a narrow pelvic inlet. The importance of several foetal-pelvic variables with regard to the mode of delivery had been pointed out in previous studies [ 7 , 12-20]. These variables are the transverse diameter and bi-spinous diameter $[12,19]$, the mid-plane antero-posterior diameter [20], the inlet and mid-plane circumference [13-17], the bi-parietal diameter [7, 18], and the head and abdominal circumference [13-17].

Our results suggested that a heavier weight at birth is associated with CD. This finding did not confirm those of previous studies, most of which considered the birth weight as irrelevant for the prediction of delivery outcome $[13,14,17]$. These previous studies used ultrasound for antenatal assessment; most of the time, this is inaccurate because of an error rate in the range of $6.4-10.7 \%$ [21]. In this study, the birth weight was not estimated but was measured on a scale. This variable was more reproducible and accurate than what can be obtained by ultrasound estimation.

We found that the obstetric conjugate was not a useful variable. This finding was consistent with results of previous studies. Laube et al. [19] found no significant difference in the obstetric conjugate between patients that delivered vaginally or abdominally. The uselessness of the obstetric conjugate can be explained by its location above the inlet plane. This plane includes the culmen of the obstetric conjugate, the arcuate lines of the ilium, and the sacrum under the promontory level of the 1st sacral vertebra (Fig. 2). Our results suggested that the antero-posterior diameter of the pelvic inlet was more relevant in identifying foetal-pelvic disproportion than the obstetric conjugate. The obstetric conjugate should no longer be considered a useful variable in estimating the arrest of labour. The antero-posterior inlet diameter is a sagittal variable that should be taken into account.

Our data showed that women with a reduced inter-spinous diameter were more at risk of requiring a CD. This finding supports those of Morgan and Thurnau [17], who found that radiographic measurements of the mid-pelvis circumference were predictive of operative delivery.

Table 3. Well-classified mother-foetus pairs according to partial least squares-discriminant analysis

\begin{tabular}{lll}
\hline & $n$ & $\%$ \\
\hline $\begin{array}{l}\text { Model } \\
\quad \text { SVD versus CD }\end{array}$ & 76 & 84 \\
Groups & & \\
$\quad$ SVD & 51 & 92 \\
CD & 25 & 68 \\
\hline Model & & \\
$\quad$ SVD versus IAD & 89 & 71 \\
Groups & & \\
$\quad$ SVD & 51 & 80 \\
IAD & 38 & 58 \\
\hline
\end{tabular}

SVD, spontaneous vaginal delivery; CD, caesarean delivery; $\mathrm{IAD}$, instrument-assisted delivery.

Fig. 4. Classification of the variables in the SVD versus CD model: 30 variables are important (i.e., with a variable importance in the projection $>1$ ). Grey shows variables allocating mother-foetus pairs to the CD group when their values were high. White shows variables allocating mother-foetus pairs to the SVD group when their values were high. For explanation of abbreviations, see Figure 3.

Fig. 5. Classification of the variables in the SVD versus IAD model: 20 variables are important (i.e., with a variable importance in the projection $>1$ ). Grey shows variables allocating mother-foetus pairs to the IAD group when their values were high. White shows variables allocating mother-foetus pairs to the SVD group when their values were high. For explanation of abbreviations, see Figure 3.

(For Figures see next page.)

Frémondière/Thollon/Adalian/Delotte/ Marchal 


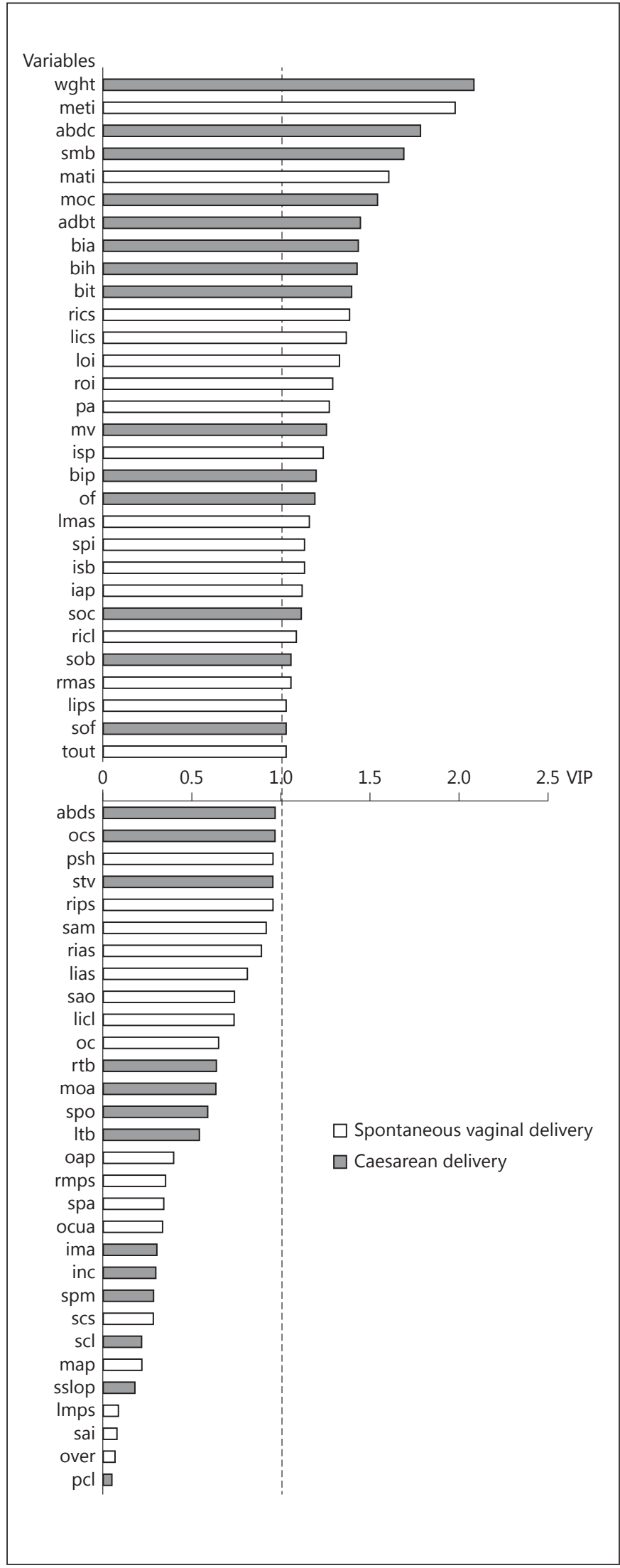

Foetal-Pelvic Variables
5

Variables
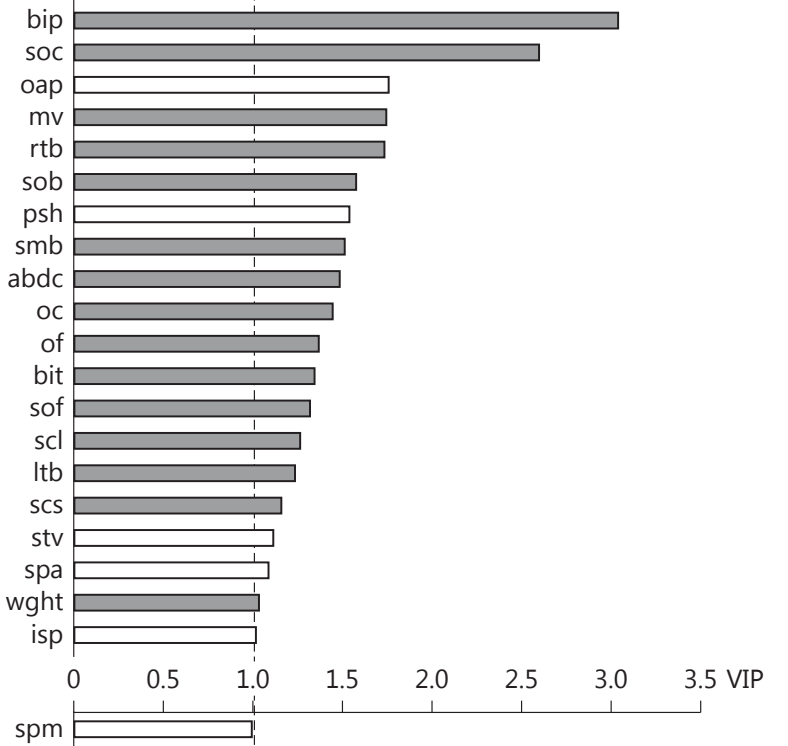

$\mathrm{pcl} \square$

tout $\square$ !

rips $\square$

lips $\square$

isb $\square$

bih $\square$

over $\square$

sao $\square$

loi $\square$

ocs $\square$

abds

Imps $\square$

rmps $\square$

map

abdt

sslo $\square$

$\mathrm{moc}$

lias

spi

prpd $\square$

sam $\square$

mati $\square$

moa $\square$

ricl $\square$

rics $\square$

sai $\square$

rias $\square$

ima $\square$

lics $\square$

roi $\square$

spo $\square$

iap $\square$

lias $\square$

inc $\square$

bia $\square$

licl $\square$

rmas

meti

pa $]$

$\square$ Spontaneous vaginal delivery

$\square$ Instrumental assisted delivery 
In this study, we found that the foetuses with large heads and the women with a reduced antero-posterior outlet diameter, a large obstetric conjugate, and a narrow pubic arch were more at risk of requiring an IAD. This combination of pelvic features is also called "funnelshaped pelvis" $[22,23]$. Our findings confirmed those of previous studies $[22,23]$, which showed the influence that a funnel-shaped pelvic plays in pelvic arrest.

We are aware that our research had several limitations. The first was the size of the CD group; only 25 women belonged to this group because of the lack of a pelvic scan. The addition of 25 more women in this group would permit us to compare groups of homogenous size.

Our sample size $(n=114)$ seemed to be sufficient to analyse the variability of the foetal-pelvic relationship. Fischer and Mitteroecker [24] based their analysis on a sample of 99 individuals and Walrath and Glantz [25] studied the variability of mid-plane shape based on 81 individuals.

Another limitation was our use of anthropometric tools. Our procedure for measuring neonates is not applicable in a predictive context, where ultrasound examination is more appropriate. However, ultrasonic imaging is limited by its spatial resolution and contrast [26]; these can reduce the precision of measurements. Our measurements were postnatal and were not affected by image resolution.

In our study, indications for a pelvic scan were a scarred uterus, a breech presentation, and suspicion or a history of foetal-pelvic disproportion. This is not consistent with previous studies, in which pelvimetry was found to be useful only in the case of breech presentation [2729]. Pelvic scanning should be limited to breech presentations, because it increases the likelihood of caesarean section in cephalic presentations [5].
The pelvic scan was performed before the delivery, so the physicians were able to make decisions regarding the mode of delivery and use of vacuum or forceps, based on the pelvic measurements. But this bias is limited because the neonatal measurements were unknown to the physicians and the birth weight estimations were more likely to be inaccurate [21].

\section{Conclusion}

In this study, the highest discriminatory variables regarding the mode of delivery were: birth weight, inlet transverse diameter, bi-parietal diameter, and outlet antero-posterior diameter. In future, studies should be conducted with foetal variables measured by ultrasound. Other delivery outcomes such as shoulder dystocia or persistence of occiput posterior presentations must also be considered. Only useful variables should be measured, and these measurements should then be integrated into a PLS-DA, providing a classification score to place mother-child pairs into either an eutocic or a dystocic group. The prediction of these delivery modalities may be useful to improve the management and health care of mothers and their newborns.

\section{Acknowledgement}

The authors would like to thank Rachael Lilie for her assistance in preparing this manuscript, and Olivier Bayle for his support in conducting this study. We are grateful to two anonymous reviewers for their helpful comments that greatly improved the manuscript.

\section{Disclosure Statement}

There were no conflicts of interest.

\section{References}

1 Lurie S, Raz N, Boaz M, et al: Comparison of maternal outcomes from primary cesarean section during the second compared with first stage of labor by indication for the operation. Eur J Obstet Gynecol Reprod Biol 2014;182: 43-47.

2 Zhang J, Troendle J, Reddy UM, et al: Contemporary cesarean delivery practice in the United States. Am J Obstet Gynecol 2010;203: 326.e1-e10.

3 Ferguson JE, Newberry YG, DeAngelis GA, et al: The fetal-pelvic index has minimal utility in predicting fetal-pelvic disproportion. Am J Obstet Gynecol 1998;179:1186-1192.
4 Spörri S, Thoeny HC, Raio L, et al: MR imaging pelvimetry: a useful adjunct in the treatment of women at risk for dystocia? AJR Am J Roentgenol 2002;179:137-144.

5 Pattinson RC, Farrell EE: Pelvimetry for fetal cephalic presentations at term. Cochrane $\mathrm{Da}$ tabase Syst Rev 1997;2:CD000161.

6 Maharaj D: Assessing cephalopelvic disproportion: back to basics. Obstet Gynecol Surv 2010;65:387-395.
7 Magnin P, Bremond A, Salomon B, et al: Diagram for the prognosis of the cephalo-pelvic disproportions. Application to 300 observations of pelvic narrowings. J Gynecol Obstet Biol Reprod 1975;4:975-987.

8 Anderson N, Humphries N, Wells I: Measurement error in computed tomography pelvimetry. Australas Radiol 2005;49:104-107.

9 Korhonen U, Solja R, Laitinen J, et al: MR pelvimetry measurements, analysis of inter- and intra-observer variation. Eur J Radiol 2010; 75:56-61. 
10 Imai N, Miyasaka D, Horigome Y, et al: Are measurements of sacral slopes reliable? J Clin Med Res 2014;2:57-60.

-11 Pérez-Enciso M, Tenenhaus M: Prediction of clinical outcome with microarray data: a partial least squares-discriminant analysis (PLS-DA). Hum Genet 2003;112:581-592.

12 Chassar Moir J: The use of radiographs in assessing disproportion. Br Med J 1949;4642: 1437-1440.

-13 Morgan MA, Thurnau GR, Fishburn JI: The fetal-pelvic index as an indicator of fetal-pelvic disproportion: a preliminary report. Am J Obstet Gynecol 1986;155:608-613.

14 Thurnau GR, Morgan MA: Efficacy of the fetal-pelvic index as a predictor of fetal-pelvic disproportion in women with abnormal labor patterns that require labor increases. Am J Obstet Gynecol 1988;159:1168-1172.

15 Morgan MA, Thurnau GR: Efficacy of the fetal-pelvic index in patients requiring labor induction. Am J Obstet Gynecol 1988;159:621625.
16 Morgan MA, Thurnau GR: Efficacy of the fetal-pelvic index for delivery of neonates weighing 4,000 g or greater: a preliminary report. Am J Obstet Gynecol 1988;158:11331137.

17 Morgan MA, Thurnau GR: Efficacy of the fetal-pelvic index in nulliparous women at high risk for fetal-pelvic disproportion. Am J Obstet Gynecol 1992;166:810-814.

18 Joyce DN, Giwa-Osagie F, Stevenson GW: Role of pelvimetry in active management of labor. Br Med J 1975;4:505-507.

19 Laube DW, Varner MW, Cruikshank DP: A prospective evaluation of X-ray pelvimetry. J Am Med Assoc 1981;246:2187-2188.

20 Harper LM, Odibo AO, Stamilio DM, et al: Radiographic measures of the mid pelvis to predict cesarean delivery. Am J Obstet Gynecol 2013;208:1-6.

21 Melamed N, Yogev YI, Mashiach Meizner $\mathrm{RR}$, et al: Sonographic fetal weight estimation. Which model should be used? J Ultrasound Med 2009;28:617-629.

-22 Caldwell WE, Moloy HC: Anatomical variations in the female pelvis: their classification and obstetrical significance. Proc R Soc Med 1938;32:1-30.
23 Salk I, Cetin M, Salk S, et al: Determining the incidence of gynecoid pelvis using threedimensional computed tomography in nonpregnant multiparous women. Med Princ Pract 2016;25:40-48.

24 Fischer B, Mitteroecker P: Covariation between human pelvis shape, stature, and head size alleviates the obstetric dilemma. Proc Natl Acad Sci USA 2015;112:5655-5660.

25 Walrath DE, Glantz MM: Sexual dimorphism in the pelvic midplane and its relationship to neandertal reproductive patterns. Am J Phys Anthropol 1996;100:98-100.

26 Wells PNT: Ultrasonic imaging of the human body. Rep Prog Phys 1999;62:671-722.

27 Ikhena SE, halligan AW, Naftalin NJ: Has pelvimetry a role in current obstetric practice? J Obstet Gynaecol 1999;19:463-465.

28 Rozenberg P: Is there a role for X-ray pelvimetry in the twenty-first century? Gynecol Obstet Fertil 2007;35:6-12.

29 Frémondière P, Fournié A: Fetal-pelvic disproportion and X-ray pelvimetry. Gynecol Obstet Fertil 2011;39:8-11.

Foetal-Pelvic Variables 